\title{
A dual marker label free electrochemical assay for Flavivirus dengue diagnosis
}

\author{
Adriano Santos $^{\mathrm{a}, 1}$, Paulo R. Bueno ${ }^{\mathrm{a}, *, 1}$, Jason J. Davis ${ }^{\mathrm{b}, *}$ \\ a Physical Chemistry Department, Institute of Chemistry, São Paulo State University, (Univ. Estadual Paulista, UNESP), Nanobionics Group, CEP: 14800- \\ 060 Araraquara, São Paulo, Brazil \\ b Department of Chemistry, University of Oxford, South Parks Road, Oxford OX1 3QZ, United Kingdom
}

\section{A R T I C L E I N F O}

\section{Keywords:}

Molecular diagnostics

Biosensor

Electrochemical capacitance spectroscopy

Electrochemical immittance analysis

Dengue

NS1

IgG

\begin{abstract}
A B S T R A C T
Dengue is a RNA viral illness of the genus Flavivirus which can cause, depending on the pervasiveness of the infection, hemorrhagic dengue fever or dengue shock syndrome. Herein we present an electrochemical label free approach enabling the rapid sensitive quantification of NS1 and IgG (supporting an ability to distinguish primary and secondary infections). Using a bifunctional SAM containing PEG moieties and a tethered redox thiol, both markers are detectable across clinically relevant levels by label free impedance derived redox capacitance. A subsequent frequency specific immittance function approach enables assaying (within seconds) with no impairment of analytical quality (linearity, sensitivity and variance).
\end{abstract}

\section{Introduction}

Dengue is an infection caused by the RNA virus DENV, a member of the Flavivirus genus (Parkash and Shueb, 2015). DENV virus has four different serotypes (DENV1, DENV2, DENV3 and DENV4) which can cause, depending on the incidence (first or secondary infection) (Darwish et al., 2015; Sinawang et al., 2016), dengue fever (DF), dengue hemorrhagic fever (DHF) or dengue shock syndrome (DSS) (Darwish et al., 2015). The symptoms vary from those which have little physical presentation to a severe disease status as characterized by bleeding and circulatory failure. Dengue is transmitted from one person to another by the bites (Darwish et al., 2015) of a female contaminated Aedes mosquito (Teles, 2011), which propagates in urban areas in subtropical and tropical regions (Darwish et al., 2015). Frequent outbreaks are reported in Asia-Pacific region, both central and south America and southeast of the Gulf of Mexico (Darwish et al., 2015). In Brazil alone, over a million cases of dengue were registered from January to May of 2015 and, in 2016, an increase of about 50\% was registered in the first two months of the year, over 2015 levels. Epidemics have additionally been reported in 2010 in the Philippines, the Caribbean, Central America and Sri Lanka (Darwish et al., 2015). It is important to highlight that, due to climate change (Hales et al., 2002) and an increase in global travelling (Parkash and Shueb, 2015), dengue re-emerged in 2009 in Florida (Darwish et al., 2015) and an outbreak in 2012 was reported in Portugal, the first since the 1920s (WHO World Health
Organization, 2012). It is now considered a global public health issue (Gurugama et al., 2010) where 3.6 billion people over 124 countries are estimated to be at-risk of infection (Beatty et al., 2010). In view of this scale, and in the absence of efficient vaccines or therapeutics (Teles, 2011), a rapid, accurate and practical diagnosis, enabling immediate patient management and a control of spread would be of considerable value (Sinawang et al., 2016).

Virus isolation and cultivation in vitro, followed by an immunofluorescence assay, is generally considered the "gold standard" approach for dengue detection (Parkash and Shueb, 2015; Darwish et al., 2015). Though highly specific, the methodology requires a long incubation time (7-12 days) and lab facilities with skilled personnel (Parkash and Shueb, 2015). In addition, the appropriate window for virus culturing is limited to up to 7 days following the onset of symptoms, making this methodology impractical for routine screening (Parkash and Shueb, 2015). Diagnosis based on RNA detection by reverse transcription polymerase chain reaction (RT-PCR) is used for detecting the viral RNA and, again, though specificity is high, this is a costly, laborious, and time intensive process (Parkash and Shueb, 2015; Darwish et al., 2015; Teles, 2011). The latter consists of an approximately three-hourprocedure (Vijgen et al., 2005) involving RNA isolation, the production of a single-strand complementary DNA copy, PCR amplification, separation, detection and quantification by optical (Freeman et al., 1999) or electrochemical (Zhang et al., 2010) measurements. PCR methods are, additionally, only effective shortly after disease onset (Darwish et al.,

\footnotetext{
* Corresponding authors.

E-mail addresses: prbueno@iq.unesp.br (P.R. Bueno), Jason.davis@chem.ox.ac.uk (J.J. Davis)

${ }^{1}$ www.nanobionics.pro.br.
} 
2015) and suffer from false-positives through cross-contamination with dengue virus PCR products in the laboratory. Serological tests such as MAC-ELISA (monoclonal antibody capture-enzyme linked immunosorbent assay) (Darwish et al., 2015), are not accessible in resource-limited healthcare settings nor readily portable (enzyme labeled secondary antibodies, repetitive incubation steps, and, a UV-Vis readout are required) (Darwish et al., 2015; Teles, 2011). Electroanalytical methods offer much to deal with challenges involving sensitivity, portability and additionally, can be both rapid and label free (Luo and Davis, 2013; Santos et al., 2014).

Recent studies have shown that non-structural protein 1 (NS1) can be used as a biomarker for the detection of dengue (Lima et al., 2010; Alcon et al., 2002; Xu et al., 2006). NS1 is a $\sim 45 \mathrm{kDa}$ glycoprotein (Allonso et al., 2011) expressed in infected cells and can be detected within a week of symptom onset in a concentration range of 0.04$2.00 \mu \mathrm{g} / \mathrm{mL}$ in serum of primary infected patients and $0.01-2.00 \mu \mathrm{g} /$ $\mathrm{mL}$ in secondary (Alcon et al., 2002). There are additional reports that a combined detection of NS1 antigen with antibodies (IgM and/or IgG) improves diagnostic sensitivity and aids the identification of secondary infection, critical in detecting likely severe forms of this disease (Blacksell et al., 2011; Wang and Sekaran, 2010a). NS1 represents an early stage biomarker (Alcon et al., 2002), with IgM detection possible from the third day after contamination, and persisting for approximately three months (Wang and Sekaran, 2010b). IgG levels spike 5-14 days after contamination (Wang and Sekaran, 2010b; Lima et al., 2012). In secondary infections, however, the IgG titer increases within 1-2 days to levels that are several orders of magnitude higher than observed prior to infection (Lima et al., 2012). IgG analysis thus can be used as confirmatory of secondary infection (Wang and Sekaran, 2010a, b). (see Supplementary material-section S1, SM-S1).

To date a number of low cost diagnostic platforms for NS1 have been reported, including those based on impedimetric analyses (Parkash and Shueb, 2015; Teles, 2011; Wong et al., 2016; Tai et al., 2006; Su et al., 2003; Oliveira et al., 2009; Cecchetto et al., 2015, 2017; Darwish et al., 2016). For example, Cecchetto et al. (2015) have reported an impedimetric biosensor to detect NS1 both in PBS and serum using a surface tethered anti-NS1 antibody. Similarly, Darwish et al. (2016) have reported an impedance immunosensor for NS1 detection through the multistep construction of an immobilized gold nanoparticle-anti-NS1 antibody film. Traditional impedimetric (faradaic or non-faradaic) approaches are inherently spectroscopic, with data acquisition typically across a broad range of applied AC frequencies $(1 \mathrm{MHz}$ to $10 \mathrm{mHz})$ prior to subsequent fitting of experimental data to a convenient electric circuit (Santos et al., 2014). In the dominant faradaic approach, it is additionally necessary to pre-dope with an amplifying excess of redox probe (Lisdat and Schäfer, 2008) prior using the resolved charge transfer resistance $\left(R_{c t}\right)$ as signal transduction. As an alternative, we have introduced the use of redox tagged receptor interfaces and redox capacitance $\left(\mathrm{C}_{\mathrm{r}}\right)$ (from electrochemical impedance-derived capacitance spectroscopy) as underpinning a fully label free sensory approach (Fernandes et al., 2014, 2013; Santos and Bueno, 2016). Although this approach brings significant practical advantages, by default, it also requires a full spectrum analysis. We have also introduced an immittance function methodology that enables a more facile analysis without any data fitting (Santos and Bueno, 2016; Bedatty Fernandes et al., 2015). This concept is based on the relationship between potential perturbation and measured current being described by mathematically exchangeable complex immittance functions (e.g. impedance $\mathrm{Z}^{*}$, capacitance $\mathrm{C}^{*}$, admittance $\mathrm{Y}^{*}$ and modulus $\mathrm{M}^{*}$ ). It is possible, within this, to obtain different transduction signals using only one data set without any reference to equivalent circuits (Santos and Bueno, 2016; Bedatty Fernandes et al., 2015; Patil et al., 2015). The benefit of using this approach is that it is, in essence, a "plug and play" concept wherein a sensor "chip" is coupled to the read out device, where an algorithm can be set up to search for the most sensitive function, simultaneously mapping its frequency response. In previous work we have demonstrated this application to a number of markers (Santos and Bueno, 2016; Bedatty Fernandes et al., 2015; Patil et al., 2015).

Herein we expand this approach to Dengue diagnostics using a mixed molecular film that is both passivating and redox active and compare the analytical potency of redox capacitance and electrochemical immittance methods. In so doing we present the first dual marker Dengue electrochemical assay reported to date, quantifying both markers across their clinically relevant ranges in a platform that is readily made mobile.

\section{Experimental}

\subsection{Chemicals and biochemicals reagents}

The chemicals were purchased from Sigma-Aldrich, except the PEGthiol (HS-C11-EG3-OCH $-\mathrm{COOH}, \mathrm{EG}=$ ethylene glycol) and 11-(ferrocenyl)-undecanethiol $(11 \mathrm{Fc})$ which were obtained from Prochimia [purity > 95\%]. Non-structural protein 1 (NS1) and IgG antibody (antiNS1, reactive against four different dengue viruses [I-IV]) were purchased from Abcam. Solutions of anti-NS1, NS1 and bovine serum albumin (BSA) $1 \mathrm{mg} / \mathrm{mL}$ were prepared in phosphate buffered saline (PBS) pH 7.4 containing $\mathrm{NaCl}(137 \mathrm{mmol} / \mathrm{L}), \mathrm{KCl}, 2.7 \mathrm{mmol} / \mathrm{L}$ and freshly prepared sodium phosphate $(10 \mathrm{mmol} / \mathrm{L})$. Solutions of PBS, $\mathrm{NaOH} 500 \mathrm{mmol} / \mathrm{L}, \mathrm{H}_{2} \mathrm{SO}_{4} 500 \mathrm{mmol} / \mathrm{L}, \mathrm{N}$-(3-dimethylaminopropyl)$N^{\prime}$-ethylcarbodiimide (EDC) $400 \mathrm{mmol} / \mathrm{L}, \quad N$-Hydroxysuccinimide (NHS) $100 \mathrm{mmol} / \mathrm{L}$ and sodium perchlorate $\left(\mathrm{NaClO}_{4}\right) 100 \mathrm{mmol} / \mathrm{L}$ were prepared in Milli-Q water (Millipore system with $18.2 \mathrm{M} \Omega \mathrm{cm}$ at $\left.25^{\circ} \mathrm{C}\right)$. Mixed solutions of PEG-thiol $(0.02 \mathrm{mmol} / \mathrm{L})$ and $11 \mathrm{Fc}(2 \mathrm{mmol} /$ L) were prepared in anhydrous ethanol. Commercial human serum was obtained from Sigma and used diluted in PBS at 20\% (v/v).

\subsection{Electrochemical measurements}

All experiments were performed at room temperature $\left(25^{\circ} \mathrm{C}\right)$ using $\mathrm{NaClO}_{4}$ electrolyte at $100 \mathrm{mmol} / \mathrm{L}$. Cyclic voltammetry (CV) and electrochemical impedance spectroscopy (EIS) measurements were performed using an AUTOLAB potentiostat equipped with a frequency response analysis (FRA) module Metrohm NOVA software. A threeelectrode system was used, including a gold electrode as working electrode (1.6 mm diameter from Basi), a platinum disc counter electrode and a $\mathrm{Ag} \mid \mathrm{AgCl}(3 \mathrm{~mol} / \mathrm{L} \mathrm{NaCl}$, from ALS Co., Ltd) as reference electrode. All potentials referred to in this work are relative to $\mathrm{Ag} \mid \mathrm{AgCl}(3 \mathrm{~mol} / \mathrm{L} \mathrm{NaCl})$. All solutions used were deaerated by $\mathrm{N}_{2}$ purging for $25 \mathrm{~min}$ before use.

\subsection{Surface preparation and characterization}

Gold electrodes were mechanically polished using 0.1 and $0.05 \mu \mathrm{m}$ grain-sized aluminum oxide aqueous suspensions (Buehler) followed by sonication in deionized water for $15 \mathrm{~min}$ to remove adhered particles. CVs for electrochemical desorption (see SM-S2) were performed in $\mathrm{NaOH} 500 \mathrm{mmol} / \mathrm{L}$, from -1.7 to $-0.5 \mathrm{~V}, 400$ cycles, at a scan rate of $50 \mathrm{mV} / \mathrm{s}$. Electrochemical cleaning CV's were performed in $\mathrm{H}_{2} \mathrm{SO}_{4} 500 \mathrm{mmol} / \mathrm{L}$ from 0.3 to $1.5 \mathrm{~V}, 500$ cycles, at a scan rate of $100 \mathrm{mV} / \mathrm{s}$, followed by CV gold oxide stripping in $\mathrm{H}_{2} \mathrm{SO}_{4} 500 \mathrm{mmol} / \mathrm{L}$ from 0.3 to $0.6 \mathrm{~V}, 10$ cycles, $100 \mathrm{mV} / \mathrm{s}$. Electroactive areas were calculated on the basis of cyclic voltammograms from the electrochemical cleaning step by integrating of the cathodic peak on the last scan using a value of $482 \mu \mathrm{C} / \mathrm{cm}^{2}$ (Marques et al., 2015; Goes et al., 2012). The surface roughness was determined by dividing the electro-active area by the geometric area. These determinations $\left(0.031 \pm 0.003 \mathrm{~cm}^{2}\right.$, with a corresponding surface roughness of $1.5 \pm 0.2$ ) were used to normalize subsequent electrochemical transduction signals.

The electro-active bifunctional SAMs were constructed by immersing cleaned electrodes for $20 \mathrm{~h}$ at $25{ }^{\circ} \mathrm{C}$ in a mixed solution containing $0.02 \mathrm{mmol} / \mathrm{L}$ PEG-thiol (with low fouling features) (Alcantar et al., 
a)

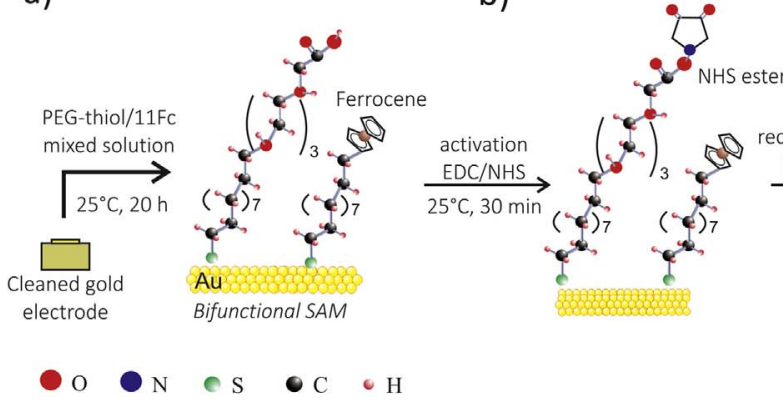

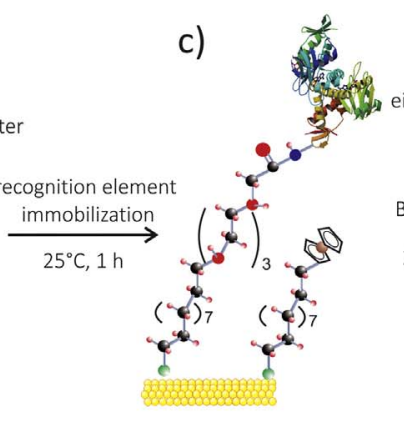

d)

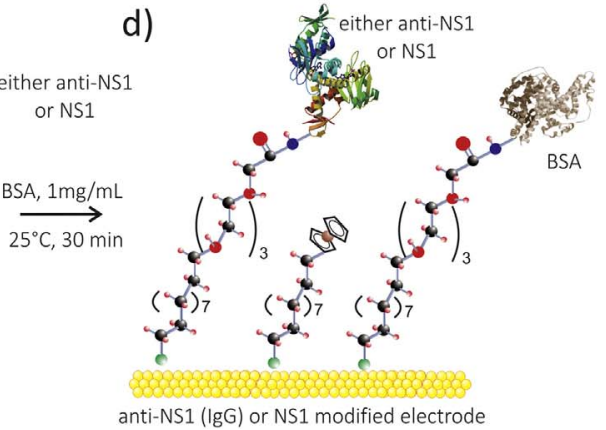

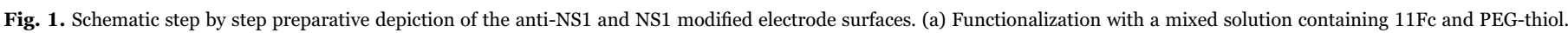

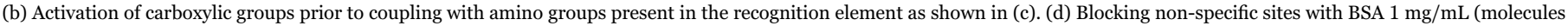
not drawn into scale).

2000; Chen et al., 2010; Zhu, 2010) and $2.0 \mathrm{mmol} / \mathrm{L} 11 \mathrm{Fc}$ in anhydrous ethanol. The carboxyl group of the PEG-thiol was then activated with an aqueous solution containing EDC $200 \mathrm{mmol} / \mathrm{L}$ and NHS $50 \mathrm{mmol} / \mathrm{L}$ for $30 \mathrm{~min}$. Subsequently, the electrode was washed using water, dried with nitrogen gas and immersed in either $97 \mu \mathrm{g} / \mathrm{mL}$ anti-NS1 solution or $10 \mu \mathrm{g} / \mathrm{mL}$ NS1 antigen in PBS for $1 \mathrm{~h}$. Finally, the electrodes were immersed in a BSA solution $(1 \mathrm{mg} / \mathrm{mL})$ for $30 \mathrm{~min}$ (Fig. 1) and then washed with PBS and water.

After SAM formation, CV analysis was performed from 0.0 to $0.8 \mathrm{~V}$ (50 cycles) at a scan rate of $100 \mathrm{mV} / \mathrm{s}$ to resolve the redox-in potential $E_{i n}=\left(E_{o x}+E_{r e d}\right) / 2$, where $E_{o x}$ and $E_{r e d}$ are the oxidation and reduction potentials peak potentials, respectively. Impedance analyses were carried out at $E_{\text {in }}$ in a frequency range of $100 \mathrm{kHz}$ to $0.1 \mathrm{~Hz}(50$ frequencies logarithmically arranged), at an amplitude of $10 \mathrm{mV}$ after each step of the interface construction.

Electrochemical capacitance analysis was performed by determining the capacitance from raw impedance data using the relationship $C^{*}(\omega)=1 / i \omega Z^{*}(\omega)$, where $\omega$ is the angular frequency and $i$ is the complex number $i=\sqrt{-1}$ Bueno et al. (2012). In processing $Z^{*}(\omega)$, it is possible to obtain both the imaginary $C^{\prime \prime}=\varphi Z^{\prime}$ and real $C^{\prime}=\varphi Z^{\prime \prime}$ portions of capacitance, noting that $\varphi=1 /\left(\omega|Z|^{2}\right)$, where $|Z|$ is the modulus of impedance. The $11 \mathrm{Fc}$ coverage $\left(\Gamma_{11 F c}, \mathrm{~mol} / \mathrm{cm}^{2}\right)$ was calculated from $\Gamma_{11 F c}=4 C_{r} k_{B} T / e F$, where $C_{r}$ is the electrochemical or redox capacitance per $\mathrm{cm}^{2}$ (estimated by the diameter semicircle of the capacitive Nyquist plot, as detailed in references (Santos et al., 2014; Fernandes et al., 2014)), $k_{B}$ is the Boltzmann constant, $T$ is the absolute temperature $(293 \mathrm{~K}), F$ the Faraday constant, and $e$ the elementary charge (Piccoli et al., 2016). $\Gamma_{11 F c}$ results obtained using redox capacitance were compared with those estimated from classical voltammetry, $\Gamma_{11 F c}=Q / F A$, assuming $F c^{+}+e^{-} \leftrightarrows F c$ and $Q$ is the charge obtained by the integration peak of the reduction/oxidation process after compensating for non-faradaic contributions (Walczak et al., 1991). $\Gamma_{11 F c}$ redox coverage was also calculated by analysis of the voltammetric current peaks resolved at different scan rates (100$700 \mathrm{mV} / \mathrm{s}$ ) (Eckermann et al., 2010a).

$\mathrm{CV}$ electrochemical desorption was performed in $\mathrm{NaOH} 500 \mathrm{mmol} /$ $\mathrm{L}$ with potential ranging from -0.2 to $-1.4 \mathrm{~V}$ at scan rate of $50 \mathrm{mV} / \mathrm{s}$ to obtain the bi-functional SAM surface coverage $\left(\Gamma_{\mathrm{SAM}}\right)$, as described elsewhere (Marques et al., 2015).

\subsection{Detection of NS1 and IgG (anti-NS1)}

After surface construction and electrochemical characterization, the functionalized electrodes were exposed for $30 \mathrm{~min}$ in either NS1 or IgG $\mathrm{mAb}$ solutions at different concentrations, ranging from 1 to $5000 \mathrm{ng} /$ $\mathrm{mL}$, prepared either in PBS or diluted serum at $20 \%(\mathrm{v} / \mathrm{v})$ in PBS. The electrodes were then washed with water and impedance analyses carried-out at $E_{\text {in }}$ using $\mathrm{NaClO}_{4}$ supporting electrolyte. A typical acquisition time of impedance data over the full frequency range (50 frequency points, $100,000-0.1 \mathrm{~Hz}$ ) is approximately $4 \mathrm{~min}$. All assays were carried out in triplicate and results reported as average \pm standard deviation $\left(\bar{x}_{ \pm} s d\right)$.

As noted above, the signal transduction $(S)$ used herein was initially the inverse of redox capacitance (i.e. $S=1 / C_{r}$, where $C_{r}$ is obtained from the semicircle diameter of the complex capacitance plots) and then the inverse of the imaginary part of capacitance (i.e. $S=1 / C^{\prime \prime}$ ). The relative response $(R R)$, defined as:

$R R_{[\text {target }]}(\%)=\left[\left(S_{[\text {target }]}-S_{0}\right) / S_{0}\right] x 100$

where $S_{0}$ represents the blank measurement and $S_{\text {[target] }}$ is the $S$ value for a certain target (either NS1 or anti-NS1) concentration. Analysis of correlation coefficient (R), coefficient of determination $\left(R^{2}\right)$, sensitivity (slope of the linear regression in the analytical plot), limit of detection (LOD, defined as $3.3 \times \mathrm{SD}$ where SD represents the standard deviation of the blank) (Long and Winefordner, 1983) and relative standard deviation (RSD) were performed. In order to evaluate non-specific interactions, serum at $20 \%$ (5 fold) dilution in PBS was used. In optimizing analytical frequency for $1 / \mathrm{C}$ " transduction analytical plots were resolved with a coefficient of determination $R^{2}>0.96$, with the highest sensitivity and the lowest limit of detection.

\section{Results and discussion}

\subsection{Surface film characterization}

An initial CV analysis of the $11 \mathrm{Fc}$ and PEG-thiol SAM (Fig. 2a) resolves the expected reversible redox wave (peak separation $30 \pm 5 \mathrm{mV}$ and current peak ratio about unity (i.e. $\mathrm{i}_{\mathrm{pa}} / \mathrm{i}_{\mathrm{pc}} \approx 1$ ). The full width at half of the peak maximum height (FWHM), a representation of redox site homogeneity (Eckermann et al., 2010b), is $\approx 110 \mathrm{mV}$ a little higher than the theoretical ideal for a one electron process $(90.6 \mathrm{mV}$ ) (Eckermann et al., 2010b), but fully in line with prior reports (Eckermann et al., 2010a). A complete impedance characterization of the bifunctional SAM is shown in SM-S3.

The $11 \mathrm{Fc}$ surface coverage $\left(\Gamma_{11 \mathrm{Fc}}\right)$ determined by integration of $\mathrm{CV}$ peaks (Fig. 2a) is $(1.8 \pm 0.5) \times 10^{-10} \mathrm{~mol} / \mathrm{cm}^{2}$. A similar value can be obtained using the linear dependence of the anodic or cathodic current peaks in function of scan rate (inset in Fig. 2a), namely $(1.4 \pm 0.3) \times$ $10^{-10} \mathrm{~mol} / \mathrm{cm}^{2}$. For comparison, an approximation based in the redox capacitance (using an approximation of the number of states at $\mathrm{E}_{\text {in }}$ energy level) (Bueno and Davis, 2014) is $(1.0 \pm 0.1) \times 10^{-10} \mathrm{~mol} / \mathrm{cm}^{2}$. The total SAM surface coverage $\left(\Gamma_{\mathrm{SAM}}\right)$ was evaluated by integrating the anodic peak (at $\approx-1.1 \mathrm{~V}$ ) (Pensa et al., 2012) (details in SM-S4) with a value of $\Gamma_{\mathrm{SAM}}=(5 \pm 2) \times 10^{-10} \mathrm{~mol} / \mathrm{cm}^{2}$, in line with expectations for films of this type (Love et al., 2005).

The impedance behavior of the mixed SAM was studied at two different potentials, redox in $\left(\mathrm{E}_{\mathrm{in}}=406 \pm 4 \mathrm{mV}\right)$ and redox out $\left(\mathrm{E}_{\text {out }}=\right.$ $100 \mathrm{mV}$ ) as previously specified. The Redox in potential corresponds to 
a)

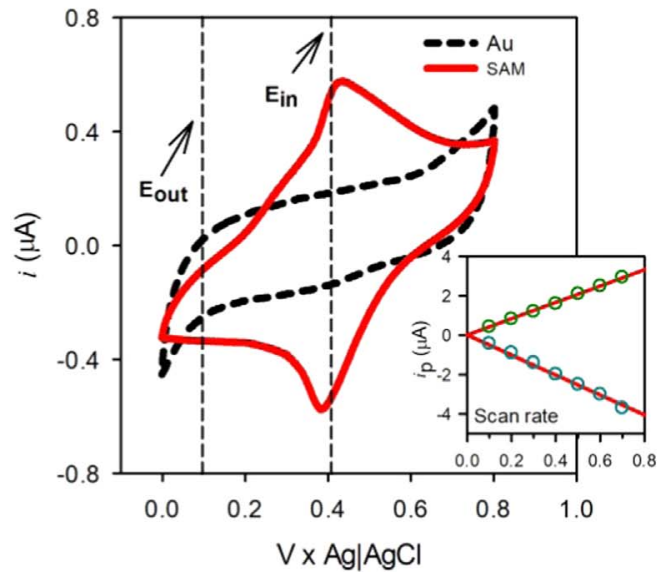

b)

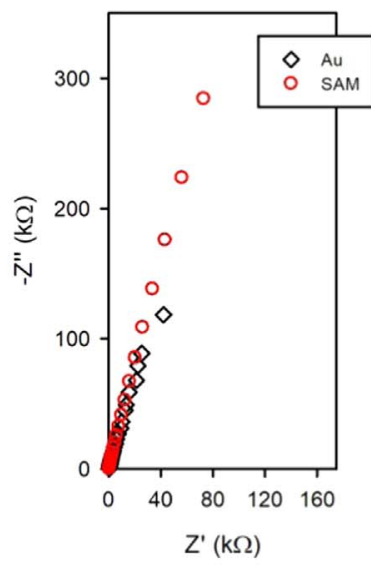

c)

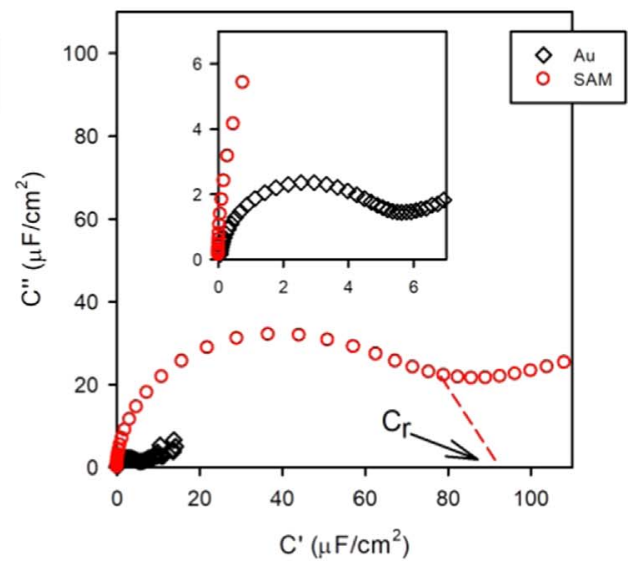

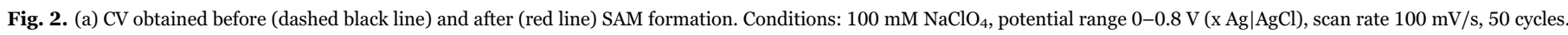

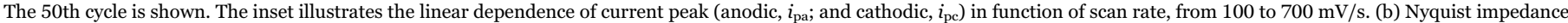

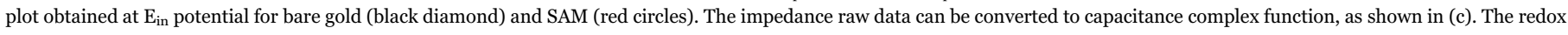

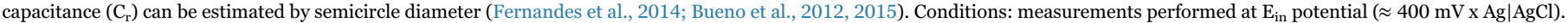

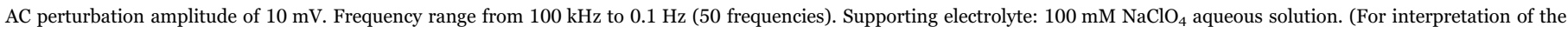
references to color in this figure legend, the reader is referred to the web version of this article.)

the formal potential of the ferrocene couple, while redox out is only a charging potential, as illustrated in the vertical lines in Fig. 2a (details of SAM impedance behavior can be found in SM-S3). From the Fig. 2b, it is not possible to distinguish the differences in the impedance Nyquist plot (i.e. complex domain) from the data collected at $\mathrm{E}_{\text {in }}$ for bare gold and SAM modified surfaces. However, this problem can be overcome by converting the complex impedance raw data to capacitance. As can be seen, at the redox in potential for bare gold, only the double layer capacitance can be noted, $5 \pm 1 \mu \mathrm{F} / \mathrm{cm}^{2}$. After SAM modification, the capacitance increases considerably $\left(96 \pm 14 \mu \mathrm{F} / \mathrm{cm}^{2}\right.$, associated with $C_{r}$ from tethered redox SAM), with a $C_{r}$ magnitude consistent with previous work $\left(\approx 100 \mu \mathrm{F} / \mathrm{cm}^{2}\right.$ ) (Bueno et al., 2013).

After SAM formation and electrochemical assessment, the carboxylic groups present in the PEG-thiol were activated with EDC/NHS chemistry (Fischer, 2010) for IgG antibody (anti-NS1) or antigen (NS1) receptor coupling. To minimise nonspecific interactions, BSA at $1 \mathrm{mg} /$ $\mathrm{mL}$ PBS was used. During both steps it was possible to observe a specific decrease in $C_{r}$ signal (Fig. S5) (Lehr et al., 2014). For more details, please refer to SM-S5.

After initial electrochemical characterization, the redox active receptive films were applied to target detection. Control receptive films are unresponsive to successive incubations in PBS or serum (demonstrating specificity and signal stability - see SM-S6 and SM-S7).

\subsection{NS1 detection in PBS and diluted serum}

For the NS1 assay, the target protein was diluted in both PBS (pH 7.4) and diluted serum (1:4, sera:PBS) across a clinically relevant concentration range $1-5000 \mathrm{ng} / \mathrm{mL}$ (Alcon et al., 2002). Aliquots of $50 \mu \mathrm{L}$ of NS1 solution were used with an incubation time of $30 \mathrm{~min}$ Fig. 3 shows the capacitance Nyquist and Bode plots subsequently obtained. All measurements were performed at the $\mathrm{E}_{\text {in }}$ potential (note that at $\mathrm{E}_{\text {out }}$ the capacitance is unresponsive to target recognition). A decrease in redox capacitance signal (semicircle diameter) was observed, as expected (Fernandes et al., 2014, 2013; Santos et al., 2014). It is worth noting that the relative response $\mathrm{RR}$ as a function of target concentration (i.e. $\mathrm{RR}(\%)=100^{*}\left(1 / C_{r,[\mathrm{NS} 1]}-1 / C_{r \text {,blank }}\right) /\left(1 / C_{r \text {,blank }}\right)$, where $C_{r,[\mathrm{NS} 1]}$ is the redox capacitance signal for a specified NS1 concentration and $C_{r \text {,blank }}$ the signal of the blank) is Langmuir in form (details in SM-S8). The derived association affinity, $K_{a}=(6 \pm 2) \times 10^{8} \mathrm{~L} / \mathrm{mol}\left(K_{D}=(1.8 \pm 0.6) \mathrm{nmol} / \mathrm{L}\right)$ is in the expected range (Fernandes et al., 2014).
From a constructed analytical curve (Fig. 4) and derived analytical parameters (Table 1), it is demonstrable that NS1 across a 1-5000 ng/ $\mathrm{mL}$ linear range is detectable with a sensitivity of $4.5 \%$ per decade. The associated LOD is $340 \mathrm{pg} / \mathrm{mL}$, lower than reported by others using carbon nanotube-screen printed electrodes $(12 \mathrm{ng} / \mathrm{mL}$ ) (Dias et al., 2013) or by means of conventional faradaic impedance using a redox probe in solution ( $3 \mathrm{ng} / \mathrm{mL}$ ) (Cecchetto et al., 2015). The average of the relative standard deviation $(R S D)$ for all data points on the calibration curve $(R S D=s d / \overline{R R}$, where $\overline{R R}$ is the relative signal average for a certain target concentration, and $s d$ the respective standard deviation) was 8.7\%. As shown in Fig. S8 (SM-S7), nonspecific responses using diluted serum at $20 \%$ were typically $<14 \%$ of those which are target specific.

The same approach was applied to detect NS1 in diluted human serum at $20 \%$. The standard curve is shown in Fig. $4 \mathrm{~b}$ (red squares) and the analytical parameters are summarised in Table 1. the methodology reported here presents a clinical relevant linear range of target concentration from $5-1,000 \mathrm{ng} / \mathrm{mL}$, since NS1 is present in patients in concentrations from 40 to $2000 \mathrm{ng} / \mathrm{mL}$ in primary and $10-2000 \mathrm{ng} /$ $\mathrm{mL}$ in secondary infections, respectively. The associated LOD of $1.2 \mathrm{ng} /$ $\mathrm{mL}$ is a lower value than previously reported by traditional impedimetric approaches (Cecchetto et al., 2015).

\subsection{IgG detection in PBS and diluted serum}

In an extrapolation of this approach to surfaces constraining the NS1 antigen, anti-NS1 (IgG) assays can be developed. The resulting (Bode and Nyquist plots) are shown in SM-S9. Robust detection was possible across a log linear range of $1-1000 \mathrm{ng} / \mathrm{mL}$ with a sensitivity of $6.3 \%$ per decade (Fig. 5a) and LOD of 231 pg/mL. As shown in Fig. S7 (SM-S7), the nonspecific responses are $<14 \%$ of specific response. In spiked dilute serum the relevant assay range is $10-1000 \mathrm{ng} / \mathrm{mL}$, with a LOD of $6100 \mathrm{pg} / \mathrm{mL}$.

\subsection{An alternative signal transduction: using $1 / C$ " immittance function}

Although the label free EIS-derived redox capacitance approach is, then, both sensitive and analytically well-behaved in clinically-relevant immunorecognition, assay times can be dramatically reduced by moving to an immittance platform (with no change in the interface or the experiment otherwise). In previous work, we have identified the 
a)

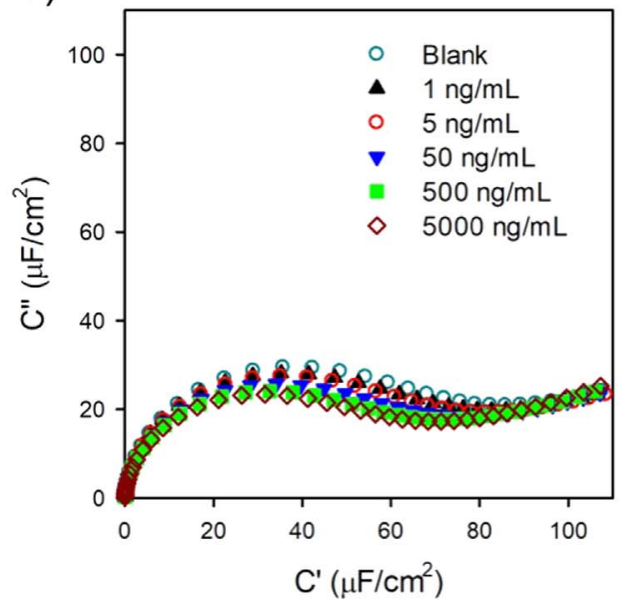

b)

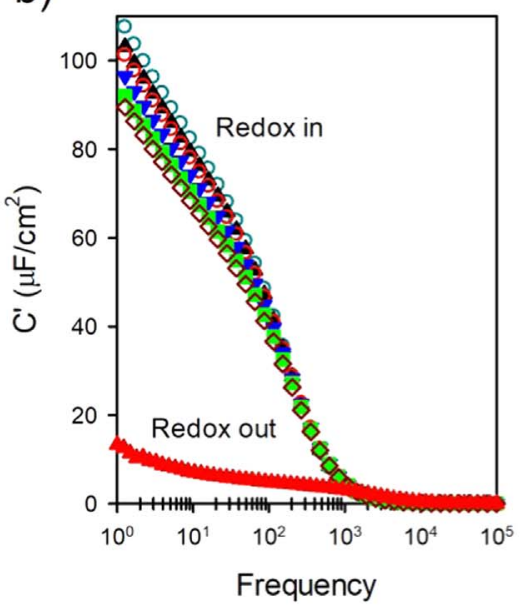

c)

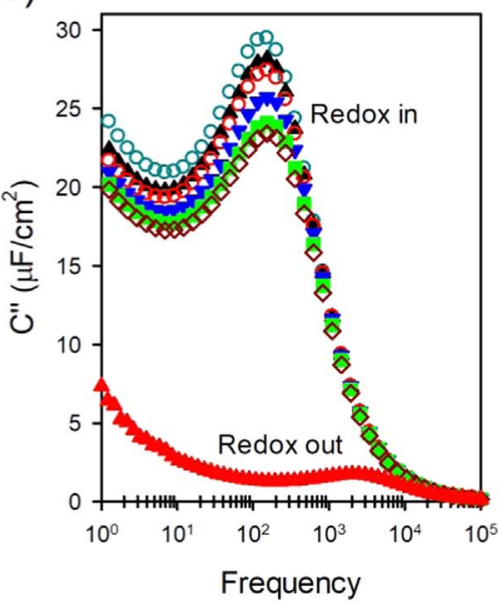

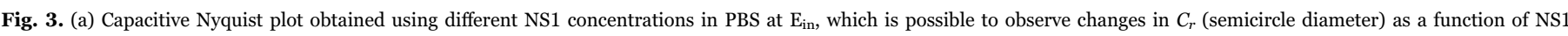

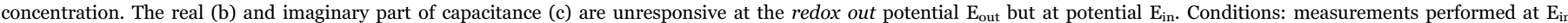

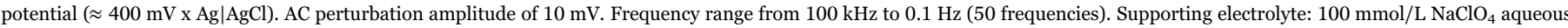
solution.

a)

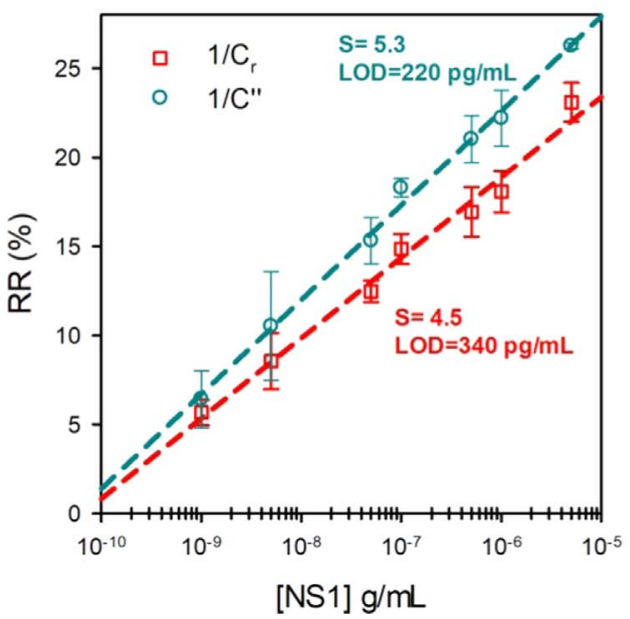

b)

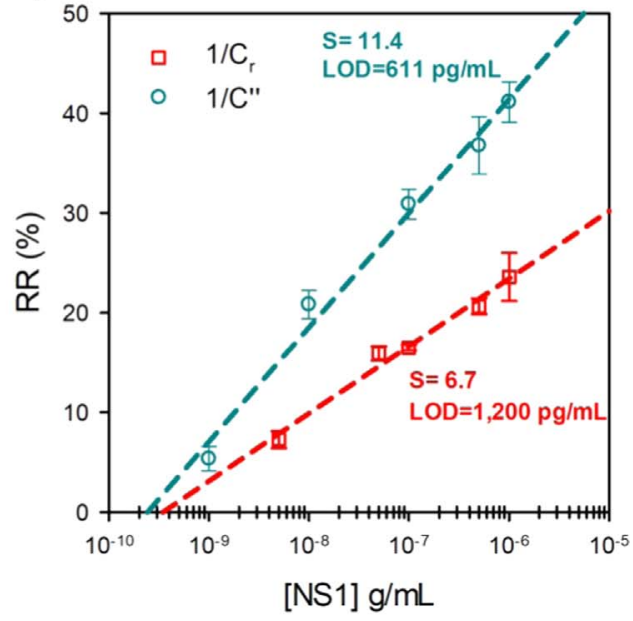

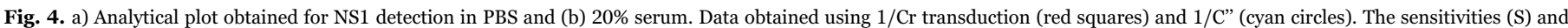

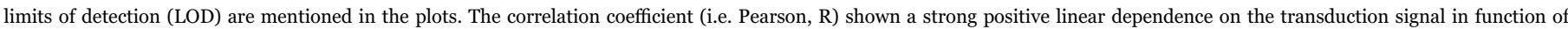

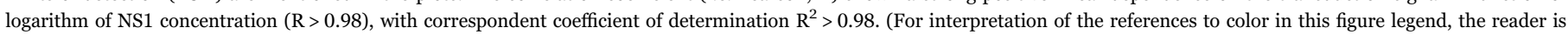
referred to the web version of this article.)

Table 1

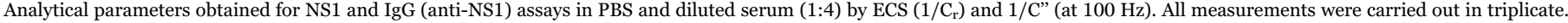

\begin{tabular}{|c|c|c|c|c|c|c|c|}
\hline Target & Approach & Assay condition & linear range $(\mathrm{ng} / \mathrm{mL})$ & Sensitivity (\% per decade) & LOD (pg/mL) & $\mathbf{R S D}^{\mathrm{a}}(\%)$ & $\mathbf{R}^{2}$ \\
\hline \multirow[t]{4}{*}{ NS1 } & \multirow[t]{2}{*}{$1 / \mathrm{C}_{\mathrm{r}}$} & PBS & $1-5000$ & 4.5 & 340 & 8.7 & 0.987 \\
\hline & & Diluted serum & $5-1000$ & 6.7 & 1200 & 7.0 & 0.983 \\
\hline & \multirow[t]{2}{*}{$1 / C "$} & PBS & $1-5000$ & 5.3 & 220 & 11.3 & 0.995 \\
\hline & & Diluted serum & $1-1000$ & 11,4 & 611 & 9.4 & 0.987 \\
\hline \multirow[t]{4}{*}{ IgG } & \multirow[t]{2}{*}{$1 / \mathrm{C}_{\mathrm{r}}$} & PBS & $1-1000$ & 6.3 & 231 & 7.0 & 0.975 \\
\hline & & Diluted serum & $10-1000$ & 16.9 & 6100 & 5.0 & 0.965 \\
\hline & \multirow[t]{2}{*}{$1 / C^{\prime \prime}$} & PBS & $1-1000$ & 6.3 & 393 & 3.4 & 0.995 \\
\hline & & Diluted serum & $10-1000$ & 15.7 & 9500 & 4.2 & 0.961 \\
\hline
\end{tabular}

a Average standard deviation calculated from analytical curve data points.

inverse of imaginary capacitance as an effective transducer signal of molecular recognition at higher analytical frequencies of a redox tagged interface $(\sim 7-100 \mathrm{~Hz})$ when compared with purely capacitance analysis as described in the previous section (Santos and Bueno, 2016; Bedatty Fernandes et al., 2015). Accordingly, the optimized frequency found is of $100 \mathrm{~Hz}$ (Fig. 6). The target-responsive data shown in Fig. 6, for example, is acquired in $<4 \mathrm{~s}$ at this frequency. The derived analytical data shown in Figs. 4 and 5, and described in Table 1 (resolving likewise a sensible association constant $\left[K_{a}=(8 \pm 2) \times 10^{8} \mathrm{~L} /\right.$ mol, details in SM-S8] confirms the validity of the approach. 
a)

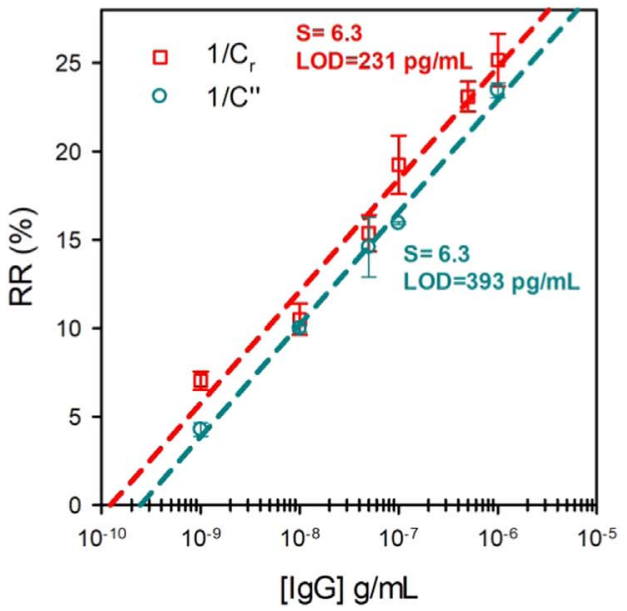

b)

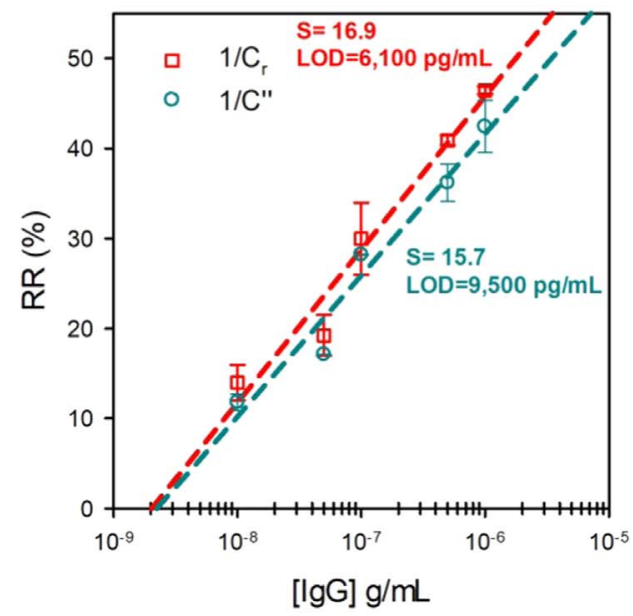

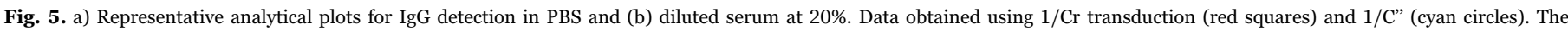

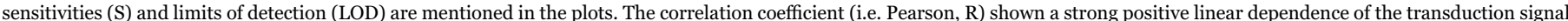

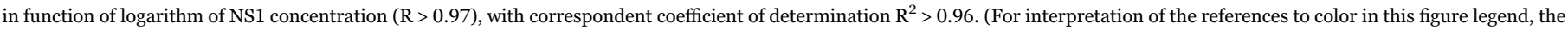
reader is referred to the web version of this article.)

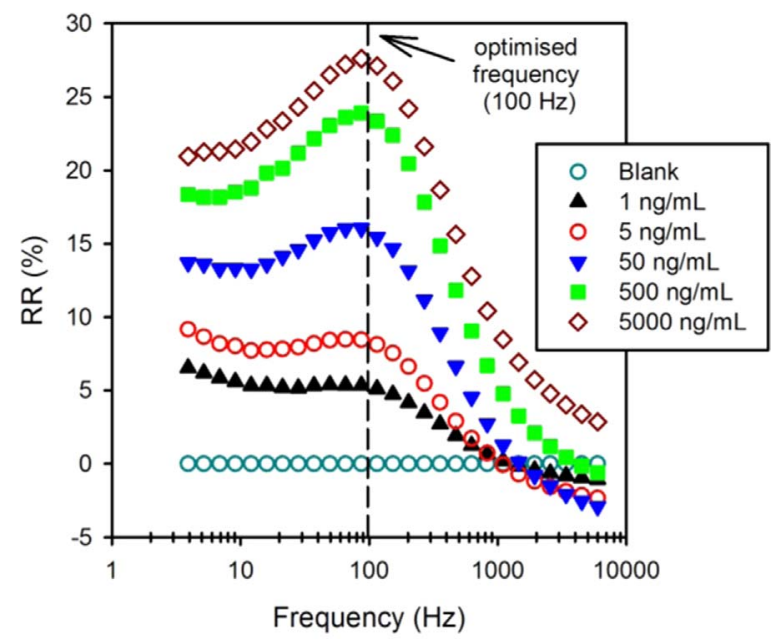

Fig. 6. Example of 1/C" immittance function obtained for NS1 detection in PBS. The optimized frequency, $100 \mathrm{~Hz}$, corresponds to the most sensitive response with $\mathrm{R}^{2}>0.96$.

\section{Conclusions}

New methodologies for dengue detection are required since the standard methods typically suffer from long data acquisition time and the need for skilled personnel. Standard impedimetric approaches, although label free and sensitive, require an amplifying pre-doping of each analytical solution with redox probe and the acquisition of data across a broad range of frequencies prior fitting to an equivalent circuit representing the electrical response of the interface. Redox capacitive methods are cleaner, equivalently sensitive and, as shown, can be additionally improved in such a way that acquisition times are significantly reduced. Here we demonstrated that both dengue primary antigen and antibodies are reliably assayed in serum across clinically relevant ranges in a few seconds. This study is readily extrapolated to include the real-time assessment of additional markers and represents, we believe, a practically relevant contribution to dengue diagnostics.

\section{Acknowledgement}

Professor Paulo R. Bueno thanks Royal Society of Chemistry for Newton Advanced Fellowship research grant and FAPESP (Sao Paulo
State Research Foundation) under the grant 2012/22820-7. Adriano dos Santos thanks CAPES for his scholarship.

\section{Appendix A. Supporting information}

Supplementary data associated with this article can be found in the online version at doi:10.1016/j.bios.2017.09.014.

\section{References}

Alcantar, N.A., Aydil, E.S., Israelachvili, J.N., 2000. Polyethylene glycol-coated biocompatible surfaces. J. Biomed. Mater. Res. 51 (3), 343-351.

Alcon, S., et al., 2002. Enzyme-linked immunosorbent assay specific to dengue virus Type 1 nonstructural protein NS1 reveals circulation of the antigen in the blood during the acute phase of disease in patients experiencing primary or secondary infections. J. Clin. Microbiol. 40 (2), 376-381.

Allonso, D., et al., 2011. Polyclonal antibodies against properly folded Dengue virus NS1 protein expressed in E. coli enable sensitive and early dengue diagnosis. J. Virol. Methods 175 (1), 109-116.

Beatty, M.E., et al., 2010. Best practices in dengue surveillance: a report from the AsiaPacific and Americas dengue prevention boards. PLoS Negl. Trop. Dis. 4 (11), e890.

Bedatty Fernandes, F.C., et al., 2015. Optimized diagnostic assays based on redox tagged bioreceptive interfaces. Anal. Chem. 87 (24), 12137-12144.

Blacksell, S.D., et al., 2011. Evaluation of six commercial point-of-care tests for diagnosis of acute dengue infections: the need for combining NS1 antigen and $\operatorname{IgM} / \operatorname{IgG}$ antibody detection to achieve acceptable levels of accuracy. Clin. Vaccin. Immunol. 18 (12), 2095-2101.

Bueno, P.R., Davis, J.J., 2014. Elucidating redox level dispersion and local dielectric effects within electroactive molecular films. Anal. Chem. 86 (4), 1977-2004.

Bueno, P.R., Mizzon, G., Davis, J.J., 2012. Capacitance spectroscopy: a versatile approach to resolving the redox density of states and kinetics in redox-active selfassembled monolayers. J. Phys. Chem. B 116 (30), 8822-8829.

Bueno, P.R., Fabregat-Santiago, F., Davis, J.J., 2013. Elucidating capacitance and resistance terms in confined electroactive molecular layers. Anal. Chem. 85 (1), 411-417.

Bueno, P.R., Feliciano, G.T., Davis, J.J., 2015. Capacitance spectroscopy and density functional theory. Phys. Chem. Chem. Phys. 17 (14), 9375-9382.

Cecchetto, J., et al., 2015. An impedimetric biosensor to test neat serum for dengue diagnosis. Sens. Actuators B: Chem. 213 (0), 150-154.

Cecchetto, J., et al., 2017. The capacitive sensing of NS1 Flavivirus biomarker. Biosens. Bioelectron. 87, 949-956.

Chen, S., et al., 2010. Surface hydration: principles and applications toward low-fouling/ nonfouling biomaterials. Polymer 51 (23), 5283-5293.

Darwish, N.T., et al., 2016. Electrochemical immunosensor based on antibodynanoparticle hybrid for specific detection of the dengue virus NS1 biomarker. J. Electrochem. Soc. 163 (3), B19-B25.

Darwish, N.T., Alias, Y.B., Khor, S.M., 2015. An introduction to dengue-disease diagnostics. TrAC Trends Anal. Chem. 67, 45-55.

Dias, A.C.M.S., et al., 2013. A sensor tip based on carbon nanotube-ink printed electrode for the dengue virus NS1 protein. Biosens. Bioelectron. 44, 216-221.

Eckermann, A.L., et al., 2010a. Electrochemistry of redox-active self-assembled monolayers. Coord. Chem. Rev. 254 (15-16), 1769-1802. 
Eckermann, A.L., et al., 2010b. Electrochemistry of redox-active self-assembled monolayers. Coord. Chem. Rev. 254 (15-16), 1769-1802.

Fernandes, F.C.B., et al., 2013. Label free redox capacitive biosensing. Biosens. Bioelectron. 50 (0), 437-440.

Fernandes, F.C.B., et al., 2014. Comparing label free electrochemical impedimetric and capacitive biosensing architectures. Biosens. Bioelectron. 57 (0), 96-102.

Fischer, M.J., 2010. Amine coupling through EDC/NHS: a practical approach. Surf. Plasmon. Reson., 55-73.

Freeman, W.M., Walker, S.J., Vrana, K.E., 1999. Quantitative RT-PCR: pitfalls and potential. Biotechniques 26, 112-125.

Goes, M.S., et al., 2012. A dielectric model of self-assembled monolayer interfaces by capacitive spectroscopy. Langmuir 28 (25), 9689-9699.

Gurugama, P., et al., 2010. Dengue viral infections. Indian J. Dermatol. 55 (1), 68-78.

Hales, S., et al., 2002. Potential effect of population and climate changes on global distribution of dengue fever: an empirical model. Lancet 360 (9336), 830-834.

Lehr, J., et al., 2014. Label-free capacitive diagnostics: exploiting local redox probe state occupancy. Anal. Chem. 86 (5), 2559-2564.

Lima, J.R.C., et al., 2012. Interpretation of the presence of IgM and IgG antibodies in a rapid test for dengue: analysis of dengue antibody prevalence in Fortaleza City in the 20th year of the epidemic. Rev. da Soc. Bras. De. Med. Trop. 45, 163-167.

Lima, Md.R.Q., et al., 2010. Comparison of three commercially available dengue NS1 antigen capture assays for acute diagnosis of dengue in Brazil. PLoS Negl. Trop. Dis. 4 (7), e738.

Lisdat, F., Schäfer, D., 2008. The use of electrochemical impedance spectroscopy for biosensing. Anal. Bioanal. Chem. 391 (5), 1555-1567.

Long, G.L., Winefordner, J.D., 1983. Limit of detection: a closer look at the IUPAC definition. Anal. Chem. 55 (7), 712-724.

Love, J.C., et al., 2005. Self-assembled monolayers of thiolates on metals as a form of nanotechnology. Chem. Rev. 105 (4), 1103-1170.

Luo, X., Davis, J.J., 2013. Electrical biosensors and the label free detection of protein disease biomarkers. Chem. Soc. Rev. 42 (13), 5944-5962.

Marques, S.M., et al., 2015. Sensitive label-free electron chemical capacitive signal transduction for D-dimer electroanalysis. Electrochim. Acta 182, 946-952.

Oliveira, M.D.L., Correia, M.T.S., Diniz, F.B., 2009. Concanavalin A and polyvinyl butyral use as a potential dengue electrochemical biosensor. Biosens. Bioelectron. 25 (4), $728-732$

Parkash, O., Shueb, R., 2015. Diagnosis of dengue infection using conventional and biosensor based techniques. Viruses 7 (10), 2877.

Patil, A.V., et al., 2015. Immittance electroanalysis in diagnostics. Anal. Chem. 87 (2), 944-950.

Pensa, E., et al., 2012. New insights into the electrochemical desorption of alkanethiol SAMs on gold. Phys Chem Chem Phys: PCCP 14 (35), 12355-12367.

Piccoli, J.P., et al., 2016. The self-assembly of redox active peptides: synthesis and electrochemical capacitive behavior. Pept. Sci. 106 (3), 357-367.

Santos, A., et al., 2014. Impedance-derived electrochemical capacitance spectroscopy for the evaluation of lectin-glycoprotein binding affinity. Biosens. Bioelectron. 62, $102-105$.

Santos, A., Bueno, P.R., 2016. Glycoprotein assay based on the optimized immittance signal of a redox tagged and lectin-based receptive interface. Biosens. Bioelectron. 83, 368-378.

Santos, A., Davis, J.J., Bueno, P.R., 2014. Fundamentals and applications of impedimetric and redox capacitive biosensors. J. Anal. Bioanal. Tech. 0 (0).

Sinawang, Prima D., et al., 2016. Electrochemical lateral flow immunosensor for detection and quantification of dengue NS1 protein. Biosens. Bioelectron. 77, 400-408.

Su, C.-C., et al., 2003. Development of immunochips for the detection of dengue vira antigens. Anal. Chim. Acta 479 (2), 117-123.

Tai, D.-F., et al., 2006. Artificial receptors in serologic tests for the early diagnosis of dengue virus infection. Clin. Chem. 52 (n. 8), 1486-1491.

Teles, F.S.R.R., 2011. Biosensors and rapid diagnostic tests on the frontier between analytical and clinical chemistry for biomolecular diagnosis of dengue disease: a review. Anal. Chim. Acta 687 (1), 28-42.

Vijgen, L., et al., 2005. Development of one-step, real-time, quantitative reverse transcriptase PCR assays for absolute quantitation of human coronaviruses OC43 and 229E. J. Clin. Microbiol. 43 (11), 5452-5456.

Walczak, M.M., et al., 1991. Reductive desorption of alkanethiolate monolayers at gold: a measure of surface coverage. Langmuir 7 (11), 2687-2693.

Wang, S.M., Sekaran, S.D., 2010a. Evaluation of a commercial SD dengue virus NS1 antigen capture enzyme-linked immunosorbent assay kit for early diagnosis of dengue virus infection. J. Clin. Microbiol. 48 (8), 2793-2797.

Wang, S.M., Sekaran, S.D., 2010b. Early diagnosis of dengue infection using a commercial dengue duo rapid test kit for the detection of NS1, IGM, and IGG. Am. J. Trop. Med. Hyg. 83 (3), 690-695.

WHO (World Health Organization), 2012. - Dengue fever in Madeira, Portugal.; Available from: $\langle$ http://www.who.int/csr/don/2012 10 17/en/ $\rangle$.

Wong, W.R., et al., 2016. Detection of dengue NS1 antigen using long-range surface plasmon waveguides. Biosens. Bioelectron. 78, 132-139.

Xu, H., et al., 2006. Serotype 1-specific monoclonal antibody-based antigen capture immunoassay for detection of circulating nonstructural protein NS1: implications for early diagnosis and serotyping of dengue virus infections. J. Clin. Microbiol. 44 (8), 2872-2878.

Zhang, G.-J., et al., 2010. Silicon nanowire biosensor for highly sensitive and rapid detection of dengue virus. Sens. Actuators B: Chem. 146 (1), 138-144.

Zhu, J., 2010. Bioactive modification of poly(ethylene glycol) hydrogels for tissue engineering. Biomaterials 31 (17), 4639-4656. 